\title{
Research on Applying Conductive Ink in Electric- Heating
}

\author{
Chen Guo Hua \\ College of Mechanical and Electrical Engineering \\ Beijing University of Chemical Technology \\ Beijing, China \\ cghboy@163.com
}

\author{
Yin $\mathrm{HaO}$ \\ College of Mechanical and Electrical Engineering \\ Beijing University of Chemical Technology \\ Beijing, China \\ yinhao012@sina.com
}

\begin{abstract}
Conductive ink formulation is designed by changing the proportion between resin and conductive filler. Making rectangular sample which have different formulation and lengthwidth ratio through silk screen printing .Then testing and analyzing sample surface resistivity, sample surface temperature and sample ageing resistance. The results show that the surface heating temperature of sample increases with conductive fillers and length-width ratio increase, when the proportion of modified resin, graphite and carbon black is $4: 3: 1$, the length-width ratio of sample is $50: 1$, and the surface temperature maintains $43^{\circ} \mathrm{C}$ at the AC220, it can be applied to electric-heating floor. Other things being equal, just changing the surface temperature and keeping it $55^{\circ} \mathrm{C}$ at the $\mathrm{AC} 220$, it can be applied to electric-heating wall.
\end{abstract}

Keywords- conductive ink;electric-heating;surface temperature; silk screen

\section{INTRODUCTION}

With the development of electric-heating, (there are more and more researches and applications on conductive ink which is applied to electric-heating as raw materials.) The main products are electrothermal film, electric heating floor, electric mural and so on ${ }^{[1-3]}$. And electrothermal film is extensively used by people. Electrothermal film is a film that evenly heat. The production process of this film is that conductive ink is evenly printed between two layers of polyester film by silk screen printing, and then is formed by hot press. Electrothermal film-heating has more advantages than traditional heating ${ }^{[4]}:(1)$ can't produce any soot, exhaust and others pollutant (2) the efficient electric conversion and energy saving, stable electrical performance (3) Using intelligent control system which can realize household measurement and inner room temperature control, so that people can adjust temperature according to their needing. (4) small size, space saving and easy installation and stable working performance. Conductive ink is conductive and heating material of electrothermal film. And the performance of conductive ink directly determines the performance of electrothermal film. This research based on using graphite and carbon black as conductive fillers and modified EP as blinder to discussing the effect on heating temperature and power when changing the ratio between conductive filler and blinder, and printing shape of proper formula. The result can provide a theoretical basis for heating production development of different power..

\section{EXPERIMENT}

\section{A. Raw Materials}

Carbon black(30 $\mu \mathrm{m}$ Tianjin Jinqiu chemical Co.,Ltd.); graphite(30 $\mu \mathrm{m}$ Qingdao Dongkai graphite Co.,Ltd.); Modified epoxy resins(thermosetting homemade);Coupling agent(KRTTS Nanjing Shuguang chemical factory);Curing agent(Triethylenetetramine chemically pure Beijing Ruizekang Biotechnonlongy Co.,Ltd.).

\section{B. Laboratory Apparatus}

Digital thermometer(TSE-1310 Taiwan electronic industry Co.,Ltd.) Digital multimeter((VC9807A Shanghai Shendao Kemao Co.,Ltd. ) Drying oven(DFZ Beijing surui Equipment Technology Co.,Ltd.) Printing organ(homemade Beijing University of Chemical Technology machinery factory) Silk screen stencil(250 mesh Shenzhen Jiecheng Printing Company) Touch regulator(0-250V Shanghai Changjiang Electrical Appliance Factory).

\section{Raw Materials}



Figure 1. Process flow chart

\section{Formula of Conductive Ink}


TABLE I. FORMULA OF CONDUCTIVE INK

\begin{tabular}{|c|c|c|c|c|c|}
\hline \multirow{2}{*}{ Material $^{\mathbf{a}}$} & \multicolumn{5}{|c|}{ Raw } \\
\cline { 2 - 6 } & $\begin{array}{c}\text { resin } \\
/ \boldsymbol{g}\end{array}$ & $\begin{array}{c}\text { graphite } \\
/ \boldsymbol{g}\end{array}$ & $\begin{array}{c}\text { Carbon } \\
\text { black } \\
/ \boldsymbol{g}\end{array}$ & $\begin{array}{c}\text { Couplin } \\
\text { gagent } \\
/ \boldsymbol{g}\end{array}$ & $\begin{array}{c}\text { Curing } \\
\text { agent } \\
/ \boldsymbol{g}\end{array}$ \\
\hline A (8:2) & 16 & 3.0 & 1.0 & 2.08 & 0.02 \\
\hline B (7:3) & 14 & 4.5 & 1.5 & 1.82 & 0.02 \\
\hline C (6:4) & 12 & 6.0 & 2.0 & 1.56 & 0.02 \\
\hline D (5:5) & 10 & 7.5 & 2.5 & 1.30 & 0.02 \\
\hline E (4:6) & 8 & 9.0 & 3.0 & 1.04 & 0.02 \\
\hline
\end{tabular}

a. The rate of binder:filler

\section{E. Making Requirements of Sample}

Generally speaking, printing thickness of sample is related to bearing capacity of printing ink, viscosity of printing ink, hardness of scraper and so on. Printing organ which is used to make that sample can control the thickness of printing ink that can be kept on about $0.1 \mathrm{~mm}$ thickness. The meshes of silk screen consist of different rectangular size ${ }^{[5]}$. After printing, we can get five sample specifications that are $200 \times 2 \times 0.1 \mathrm{~mm}^{3}$, $200 \times 4 \times 0.1 \mathrm{~mm}^{3}, \quad 200 \times 10 \times 0.1 \mathrm{~mm}^{3}, \quad 200 \times 20 \times 0.1 \mathrm{~mm}^{3}$ and $200 \times 40 \times 0.1 \mathrm{~mm}^{3}$.

\section{RESULTS AND DISCUSSION}

\section{A. Sample’s Surface Resistivity}

TABLE II. SAMPLE SURFACE RESISTIVITY

\begin{tabular}{|c|c|c|c|c|c|}
\hline \multirow{2}{*}{ Resistivity } & \multicolumn{5}{|c|}{ Material } \\
\cline { 2 - 6 } & $\boldsymbol{A}$ & $\boldsymbol{B}$ & $\boldsymbol{C}$ & $\boldsymbol{D}$ & $\boldsymbol{E}$ \\
\hline $\mathrm{R} / \Omega \mathrm{mm}$ & $4.53 \times 10^{4}$ & 568.37 & 212.90 & 66.50 & 47.60 \\
\hline
\end{tabular}

When conductive filler is increased from $20 \%$ to $30 \%$, sample surface resistivity decreases two orders of magnitude. This is due to as the conductive filler increases, the particles form incomplete contact to complete contact, and along with it particles size shrink between each other. Final the conduct network that make sample surface resistivity sharp decrease is form. When the filler increase from $30 \%$ to $60 \%$, the increasing trend of resistivity slow down. This is because of filler exceeds the threshold level of its "percolation threshold", conductive of sample don't improve greatly.

\section{B. Surface Heating Temperature of The Sample}

We link the two ends leads of sample electrode to 220VAC, then using TSE-1310 digital thermometer to measure the surface heating temperature of sample, as shown below.

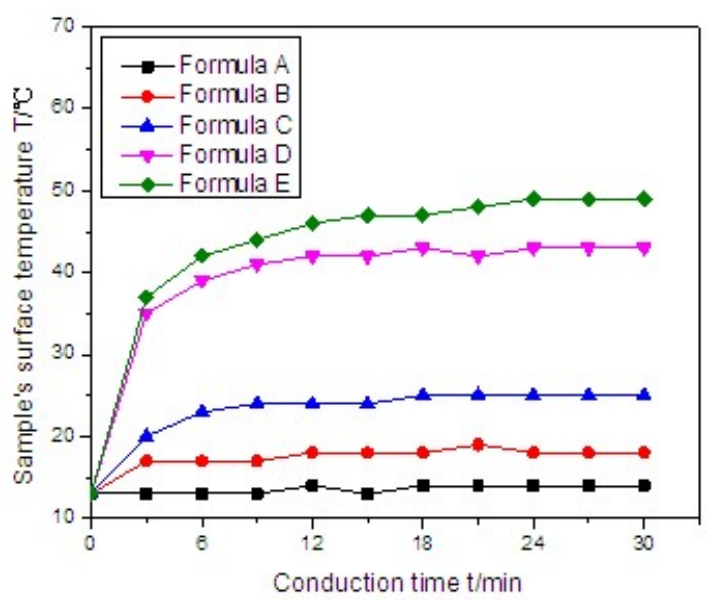

Figure 2. $200 \times 4 \mathrm{~mm}^{2}$ Sample surface heating temperature

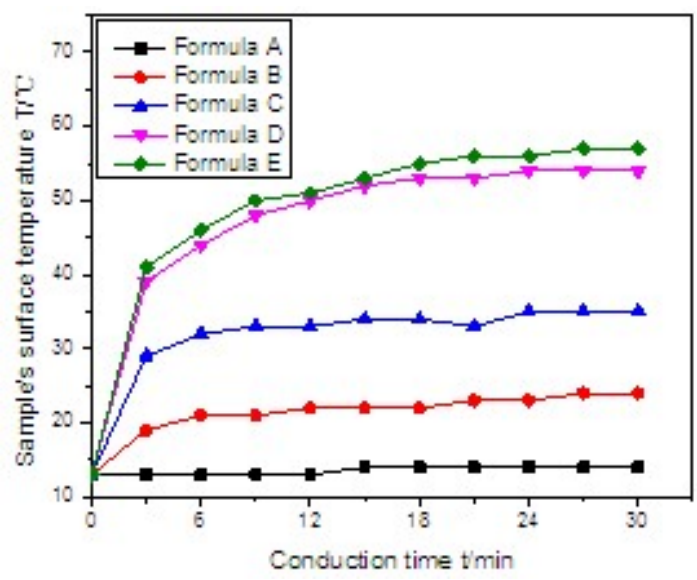

Figure 3. $200 \times 10 \mathrm{~mm}^{2}$ Sample surface heating temperature

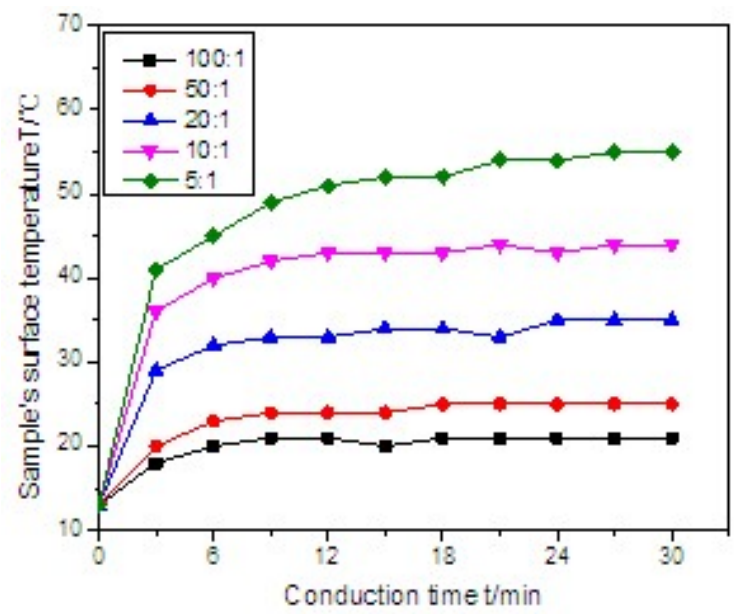

Figure 4. Formula C: Sample surface heating temperature of different lengthwidth ratio 


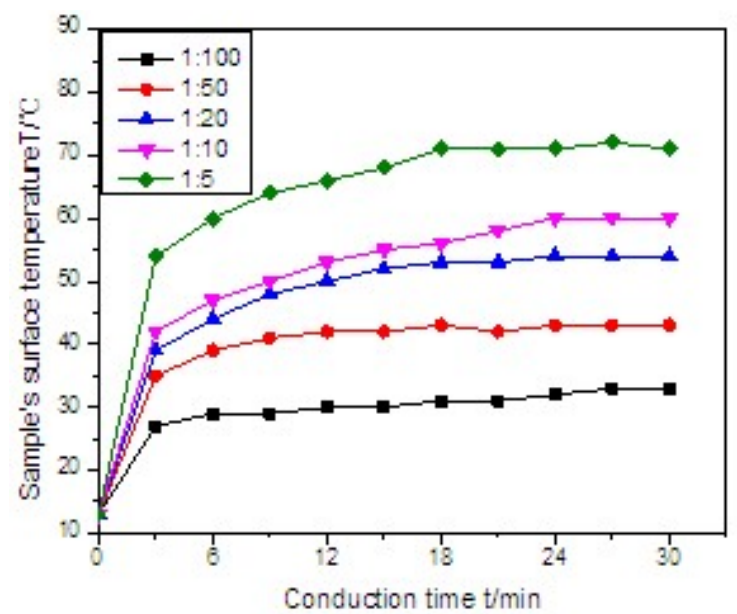

Figure 5. Formula D: Sample surface heating temperature of different length-width ratio

As the chart shows, surface heating temperature of the same shape sample gradually rising, with increased proportion of conductive filler in the formula. Using the same formula, sample surface heating temperature changing as printing shape changing. And the larger length-width ration of sample, the better heating property of sample. Thus, sample surface heating temperature is related to its formula and printing shape. Whatever any shape the formula $\mathrm{A}$ is printed, its electrothermic properties are not obvious. But the samples of formula B, C, D and $\mathrm{E}$ demonstrate different electrothermic properties. As you can see from figure, in the first three minutes after switching on the power, sample surface heating temperature increased rapidly. After 10 minutes electrothermic properties basically achieve stable. This is due to sample heating and radiating basic balance. When the sample use formula $\mathrm{D}$ and have length-width ratio of $50: 1$, its surface heating temperature is maintained $43^{\circ} \mathrm{C}$ at the AC220, as shown in Figure 2. When the sample use formula $\mathrm{D}$ or $\mathrm{E}$ and have length-width ratio of 20:1, its surface heating temperature is maintained $55^{\circ} \mathrm{C}$ at the AC220, as shown in Figure 3. When the sample use formula C and have length-width ratio of 10:1 and 5:1, its surface heating temperature is maintained $43{ }^{\circ} \mathrm{C}$ and $55^{\circ} \mathrm{C}$ respectively at the AC220, as shown in Figure. 4. Conductive filler account for a percentage of formula $\mathrm{E}$ that will make conductive ink dry faster, precipitate easily and affect its synthetical properties. When the sample surface heating temperature of formula $\mathrm{C}$ is close to the sample surface heating temperature of formula D, sample length-width ratio of formula $\mathrm{C}$ is much larger than sample length-width ratio of formula $\mathrm{D}$. And if we print the same size sample per unit area, the surface heating temperature of sample which have large length-width ratio is less uniform than the surface heating temperature of sample which have small length-width ratio. In conclusion, conductive ink of formula $\mathrm{D}$ is most suitable for electric-heating. When the sample use formula $\mathrm{D}$ and have length-width ratio of 50:1, its surface heating temperature can be maintained $43{ }^{\circ} \mathrm{C}$ at the AC220V. The conductive ink of formula D can be applied in products of electric-heating floor. When the sample use formula D and have length-width ratio of 20:1, its surface heating temperature can be maintained $43^{\circ} \mathrm{C}$ at the AC220V.
The conductive ink of formula D can be applied in products of electric-heating wall.

\section{Power Density of The Sample}

Some samples power are shown in the following tableIII.

TABLE III. SOME SAMPLES POWER

\begin{tabular}{|c|c|c|c|c|}
\hline \multirow{2}{*}{$\begin{array}{c}\text { length-width } \\
\text { ratio }\end{array}$} & \multicolumn{4}{|c|}{ Formula } \\
\cline { 2 - 5 } & $\boldsymbol{B}$ & $\boldsymbol{C}$ & $\boldsymbol{D}$ & $\boldsymbol{E}$ \\
\hline $50: 1$ & $0.26 \mathrm{~W}$ & $0.55 \mathrm{~W}$ & $1.79 \mathrm{~W}$ & $2.69 \mathrm{~W}$ \\
\hline $20: 1$ & $0.65 \mathrm{~W}$ & $1.21 \mathrm{~W}$ & $4.12 \mathrm{~W}$ & $5.70 \mathrm{~W}$ \\
\hline
\end{tabular}

The following table shows the power density of electric product which have different printing size and print the area accounts of $2 / 3$ of the total area.

TABLE IV. SOME PRODUCTS POWER DENSITY

\begin{tabular}{|c|c|c|c|c|}
\hline \multirow{2}{*}{$\begin{array}{c}\text { Print size } \\
/ \mathbf{m m}^{2}\end{array}$} & \multicolumn{4}{|c|}{ Formula } \\
\cline { 2 - 5 } & $\boldsymbol{B}$ & $\boldsymbol{C}$ & $\boldsymbol{D}$ & $\boldsymbol{E}$ \\
\hline $500 \times 10$ & $34.71 \mathrm{~W}$ & $73.70 \mathrm{~W}$ & $232.01 \mathrm{~W}$ & $360.33 \mathrm{~W}$ \\
\hline $400 \times 20$ & $53.93 \mathrm{~W}$ & $114.13 \mathrm{~W}$ & $365.43 \mathrm{~W}$ & $557.94 \mathrm{~W}$ \\
\hline
\end{tabular}

Power density of the sample is proportional to proportion of conductive filler in the formula and length-width ratio of the sample, as shown in table III. In the actual project, adopting parallel printing mode, power density of formula $\mathrm{D}$ which print size are $500 \times 10 \mathrm{~mm}^{2}$ and $400 \times 20 \mathrm{~mm}^{2}$ can achieve $232.01 \mathrm{~W} /$ $\mathrm{m}^{2}$ and $365.431 \mathrm{~W} / \mathrm{m}^{2}$, it meets the requirements of electricheating.

\section{Test Ageing of The Sample}

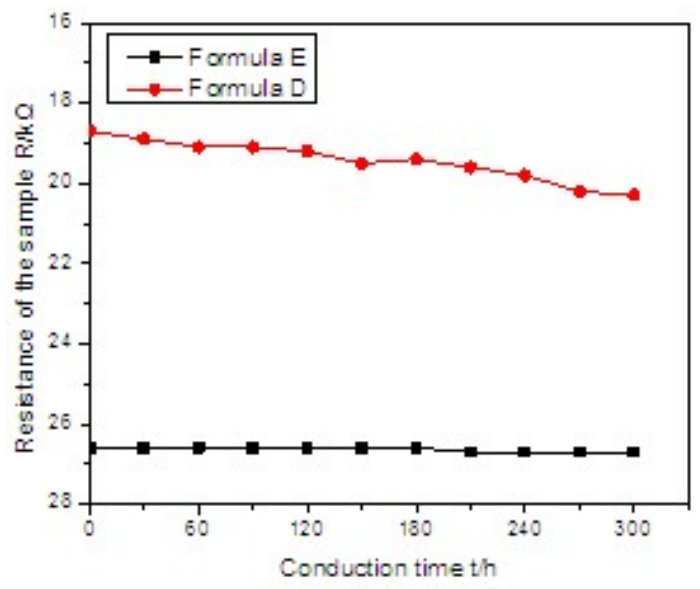

Figure 6. Formula D and $\mathrm{E}$ of the sample change in resistance

The $200 \times 4 \mathrm{~mm}^{2}$ sample of formula $\mathrm{E}$ and formula D are charged with $400 \mathrm{~h}$ electricity respectively, then test ageing resistance of the sample.

As the chart shows, formula D of sample is energized from 0 to $300 \mathrm{~h}$. The resistance of sample changed from $28.7 \Omega$ to 
$28.8 \Omega$. There is not the phenomenon of ageing. The working life of this formula sample has certain stability. Formula $E$ of the sample is energized from 0 to $300 \mathrm{~h}$, the resistance of the sample changed from $18.6 \Omega$ to $19.8 \Omega$. There is the phenomenon of ageing. This is due to the proportion of conductive filler is too high to conductive filler badly disperse in system and easily precipitate. Resistance of the place where distribute lots of conductive filler is small and resistance of the place where distribute less conductive filler is large, that causing transformation of total resistance.

\section{CONCLUSION}

After the text edit has been completed, the paper is ready for the template.

a) Surface heating temperature of the rectangular sample is related to the formula of the conductive ink and lengthwidth ratio of the sample. The larger proportion of conductive filler in system, the higher surface heating temperature of the sample. And the larger length-width ratio of the sample, the higher surface heating temperature of the sample. b) Designed the optimal formula of conductive ink suitable for heating, and the formula is $\mathrm{m}$ (resin) : $\mathrm{m}$ (graphite) : $\mathrm{m}$ (carbon black $)=4: 3: 1$. In this formulation, when the length-width ratio of sample is $50: 1$, the surface heating temperature is maintained $43^{\circ} \mathrm{C}$ at the AC220, and the power density can achieve $232 \mathrm{~W} / \mathrm{m} 2$. When the length-width ratio of sample is $20: 1$, the surface heating temperature is maintained $55^{\circ} \mathrm{C}$ at the $\mathrm{AC} 220$, and the power density can achieve $356 \mathrm{~W} / \mathrm{m}^{2}$.

\section{REFERENCES}

[1] ZHANG Z N, ZHANG G S, Study on the application of carbon system mixed filler in conductive coating [J] paint industry 1997(5): 9-11 .

[2] MA X X, WEI X F. The effect of conductive fillers on the performance of electric conductive ink used in electric radian heating film[J] Joumal of Beijing institute of graphic communication 2011,19(2): 16-18.

[3] XIA J T,TU C J. Conductive and heating coating with compound carbon-fillers[J] J.CENT.SOUTH UNIV 2005,36(2): 25-29.

[4] JIN H W. XU H a new type of heating mode- electricity heating membrane [J] . Changchun Inst. Tech. 2001,2(3): 39-40.

[5] LI J. Electric heating film and screen pribting [J] Screen pribting 1996,1: $13-17$. 